\title{
CLINICAL PERFORMANCE OF LAMBDA PLATES IN THE MANAGEMENT OF SUBCONDYLAR FRACTURES
}

\begin{tabular}{|c|}
\hline Dental Science \\
\hline
\end{tabular}

$\begin{array}{ll}\begin{array}{l}\text { Dr. Marbon } \\ \text { Joevitson* }\end{array} & \text { MDS.,FOMI.,FAM Senior Lecturer, Dept of OMFS, Sree Mookambika Institute of } \\ & \text { Dental Sciences, Kanyakumari District, Tamilnadu, India. }{ }^{*} \text { Corresponding Author }\end{array}$

\section{Dr. Annamalai Thangavelu}

\section{Dr. Eshona Pearl}

\section{Dr.}

Thiruneelakandan

MDS.,DNB.,FIBOMS Professor, Dept of OMFS, Rajah Muthiah Dental College and Hospital, Annamalai University, Chidambaram. Tamilnadu, India.

MDS Senior Lecturer, Dept of Prosthodontics. Sree Mookambika Institute of Dental Sciences, Kanyakumari District, Tamilnadu, India.

MDS.,FIBOMS Professor, Dept of OMFS, Rajah Muthiah Dental College and Hospital, Annamalai University, Chidambaram. Tamilnadu, India.

\section{Dr. Janarthanan}

MDS, Professor, Dept of OMFS, Rajah Muthiah Dental College and Hospital, Annamalai University, Chidambaram. Tamilnadu, India.

\section{ABSTRACT}

Background and Aim: Several options are available for open fixation of sub-condylar fractures. The seven-hole lambda plate is believed to demonstrate favorable outcomes for sub-condylar fractures, more so in cases with limited available bone surface. The study aimed to evaluate the outcome of sub-condylar fractures managed using lambda plates.

Method: The study comprised on 10 diagnosed cases of sub-condylar fracture indicated for open fixation and were managed using the seven-hole lambda plate. Surgery was carried out under general anesthesia following standard surgical procedure. Post surgery, the cases were evaluated for immediate post-operative complications and followed up for 6 months for delayed complications.

Results and Conclusion: All 10 cases showed excellent outcomes post fracture fixation using the lambda plate. Significant improvement in mouth opening was noted in all the cases at 6 weeks and 6 months follow up. No significant post surgical complications were noted in the cases except one where post operative pain persisted for a week. Lambda plates provide an attractive option for the management of sub-condylar fractures with minimal complications.

\section{KEYWORDS}

\section{Bone plates, Fracture fixation, Fracture healing, Lambda Plates, 3D Plates}

\section{Background and Introduction:}

The anatomy of the maxillomandibular region is complex and is prone to traumatic injuries. The mechanics of the mandibular anatomy is such that it dissipates traumatic forces by fracturing along the condylar region thus protecting the cranial fossa and its contents. Condylar fractures account for $28 \%$ of all mandibular fractures and most of these are subcondylar.

The algorithm for the management of subcondylar fractures includes the decision to follow a conservative or exploratory approach. Surgical approach presents with a plethora of plating options. There has been much research on the seven hole lambda plates for subcondylar fractures but with contradictory results. While some studies conclude that Lambda plates demonstrate poor rigidity and maximum displacement in comparison with other plates, others state that Lambda plates provide a viable option more so in neck fractures with limited bone surface. The lambda plate is a 7 hole, $1 \mathrm{~mm}$ plate which mimics the two miniplates technique with a straight segment parallel to the posterior border of the ramus and an anterior curved arm aligned to the sigmoidal notch. The lambda plate has the advantage of being able to address large fracture areas with enhanced anatomic adaptability. Based on this premise, the study aimed to appraise subcondylar fractures fixed using the Lambda plating system.

\section{METHODOLOGY:}

The study sample comprised of 10 patients who reported to the Department of Oral and Maxillofacial Surgery, Rajah Muthiah Dental College and Hospital, Tamilnmadu, India, with traumatic injuries resulting in subcondylar fractures of either one or both condyles. The study was conducted following approval by the Institutional Ethics committee. Written informed consent was obtained from the patient. Cases suitable for open fixation such as bilateral condylar fractures, considerable dislocation, cases where closed reduction seemed improbable of restoring occlusion and concomitant fractures of other bone were included in the study. Cases which were amenable to closed reduction, presence of congenital or other anomalies of the condyle, systemic conditions such as osteoporosis and other conditions altering bone morphology or impeding fracture healing, systemic illnesses where anesthesia was contraindicated were excluded from the study.
All cases were diagnosed through conventional radiography and computed tomography. Routine pre operative laboratory investigations were carried out and pre-anesthetic evaluation was done. General anesthesia was administered through naso-tracheal intubation. The surgery was performed by the same surgeon with expert training in the field of maxillo-facial surgery. Following preparation of the surgical field, the zygomatic arch, articular fossa and mandibular ramus till the angle were identified and marked on the skin. The fractured ends were outlined. A standard retromandibular incision was placed. The skin was incised, the subcutaneous tissues dissected superficial to the Superficial Muscular Aponeurotic System (SMAS) in an anterosuperior direction using blunt and sharp dissection until masseter muscle fibers appeared. Facial nerve fibers were protected with a retractor when they were detected. When the bone surface was reached, the periosteum was elevated and the fracture identified and reduced. To facilitate fracture reduction, the distal fracture fragment was mobilized caudally by applying intraoral pressure to the last mandibular molars with a finger. Once the fracture was reduced, rigid plate osteosynthesis was performed using Lambda plate. Double layered closure was done and hemostasis was achieved. All cases were prescribed post-operative antibiotics and steroids. Post operatively, the cases were evaluated for degree of mouth opening, post operative pain and swelling, Intermaxillary fixation duration, occlusal discrepancies if any, extra-oral scar, associated fractures and post operative complications. Follow up was carried out for a period of six months

\section{RESULTS:}

The study was undertaken to evaluate the efficacy of Lambda plates in the management of sub-condylar fractures. Of the 10 cases included, 4 were females and 6 males. Their ages ranged from 22 years to 70 years. (Mean=45).All 10 cases had unilateral subcondylar fracture with Road traffic accident being the cause in 9 cases and assault for one. Of the 10 cases, 8 had fractures of the left condyle while the remaining 2 of the right. Among the cases, 6 had other associated fractures such as parasymphyseal fracture of fracture of the body of the mandible. All 10 cases showed significant improvement in mouth opening at 6 weeks follow up and 6 months follow up. Intermaxillary fixation was carried out for 8 of the cases for a period of 2 weeks. Restoration of occlusion was achieved in all the cases and the only complication noticed was 
post operative pain for a period of 1 week which was managed by administration of non-opioid analgesics which subsided in all the cases thereafter. None of the cases showed post-operative infection and postoperative swelling was minimal in all the cases except two which were managed with parenteral steroids. Six months follow up showed stable osteosynthesis in all the cases.

\section{STATISTICALANALYSIS:}

The data was expressed in number, percentage, mean and standard deviation. Statistical Package for Social Sciences (SPSS 16.0) version used for analysis. ANOVA followed by Dunnett test applied to find the statistical significant. p value less than 0.05 considered statistically significant at $95 \%$ confidence interval.

Table-1: Demographic data

\begin{tabular}{|c|c|c|}
\hline Demographic data & Number (n) & Percentage (\%) \\
\hline Gender & & \\
\hline Male & 6 & 60.00 \\
\hline Female & 4 & 40.00 \\
\hline Type & & \\
\hline Unilateral & 10 & 100.00 \\
\hline Bilateral & 0 & 0.00 \\
\hline Side & & \\
\hline Right & 2 & 20.00 \\
\hline Left & 8 & 80.00 \\
\hline
\end{tabular}

Graph-1: Distribution of patients based on the age

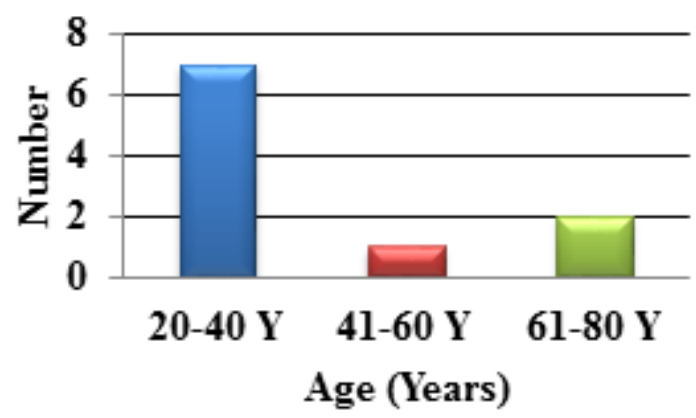

Table-2: Comparison of mouth opening of preoperative with immediate and after 6 months

\begin{tabular}{|c|c|c|}
\hline Time & Mouth opening (MEAN \pm SD) & p value \\
\hline Preoperative & $25.30 \pm 3.77$ & \multirow{0}{*0.0001}{} \\
\cline { 1 - 2 } Immediate post operative & $33.60 \pm 2.59^{*}$ & \\
\cline { 1 - 2 } $\begin{array}{c}\text { Post operative after 6 } \\
\text { month }\end{array}$ & $41.10 \pm 3.21^{*}, \#$ & \\
\hline
\end{tabular}

(* $p<0.05$ significant compared preoperative with others, $\# p<0.05$ significant compared immediate post operative with others)

Graph-2: Comparison of mouth opening of preoperative with immediate and after 6 months

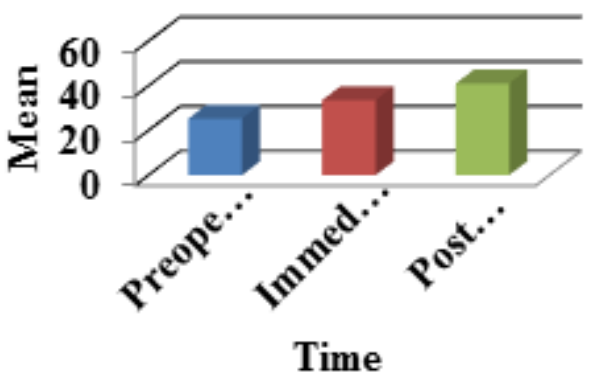

DISCUSSION:

Condylar fractures are among the most controversial of the maxillofacial injuries, in terms of diagnosis and biomechanics as well as in terms of management. Appropriate surgical management is vital to avoid long term complications such as growth impediment, asymmetry, TMJ disorders, ankylosis and impaired jaw mobility. While undertaking open reduction and rigid fixation of these fractures, the functional load which result in compressive and tensile stresses along the anterior and posterior borders of the condyle must be borne in mind and the choice of technique and armamentarium must be based on the same. Of all condylar fractures, sub-condylar fractures account for $60 \%$. The lambda plate is designed for fractures involving narrow condylar necks and sparse bone surfaces in the lateral aspect. It comprises of a linear posterior arm and an anterior arm which is cantilever with both arms having a solid intermediate bar. It roughly resembles the Greek symbol lambda $(\lambda)$ with the converging midportion providing crucial rigidity across the fracture plane. It offers the advantage of the upper arm being placed far cranially to extend over high condylar neck fractures and its ability to cover large fracture areas.

Condylar fractures could result from various causes. Road traffic accidents was the most frequent cause in all ranges of age, the second in frequency was sports injury in children and teenagers and casual accidents in adults. By gender, the most frequent etiology was road traffic accidents in both men and women. The most common cause was altercations in men and casual accidents in women. ${ }^{8}$ In this study Road Traffic Accidents were the most common cause (90\%). Assault accounted for the others (10\%).

The method of fixing the condylar fracture is either by open reduction or by closed reduction, which has always evoked controversies.' Although many systems of rigid fixation have been described, that with miniplates is the preferred technique today. Miniplate osteosynthesis provides rigid fixation that may be easily adapted to the curvature of the bone, and requires only a simple operation. Choi and Yoo compared the biomechanical stability of four different plating techniques (4-screw monocortical miniplate, 4-screw bicortical mini dynamic compression plate, 4 -screw $2.4 \mathrm{~mm}$ plate, and a double monocortical miniplate) in mandibles from formalin fixed cadavers, and found the double miniplate to be the most stable. ${ }^{10} \mathrm{~A}$ 2-plate technique is preferable if there is adequate bony substance on either side of the fracture, but fixation with two miniplates might be a more traumatic procedure than fixation with a single miniplate. Two miniplates(double-plate technique) are the most reliable because these neutralize tension and pressure forces best and produce greater stability. ${ }^{10}$ To gain more stability these two plates should be placed with a sufficient distance between the screws and the fracture line. This disadvantage was overcome by the decision of Meyer et al. to select a different design of Lambdoid-shaped plate, having taking into account the anatomical circumstances. ${ }^{11,12,13}$ These plates provide sufficient stabilization for open reduction and internal fixation of sub-condylar and condylar neck fractures combined with the advantage of a smaller plate. In the lambda-shaped plate, the longer arm is oriented toward the angle of the mandible; thus, the lines of tensile and compressive stress distribution run parallel to both sides of the plate. The tensile and compressive strains are distributed evenly along the longer arm which lies in the posterior border of ramus and along the shorter arm which lies just below the sigmoid notch. It provides better osteosynthesis when compared to a single miniplate along the posterior border and it also overcomes the disadvantages of using 2 miniplates, one at the posterior border and one below the sigmoid notch. Using the new lambdoid-shaped plate for condylar neck fractures has 3 main advantages: 1) neutralization of changing strains at the anterior, lateral, and posterior borders; 2) the additional stabilization provided by a compression miniplate; and 3) a small osteosynthesis plate. ${ }^{12}$ "Lambda plating system" can transmit the demanded loads in all directions of movement. This plate allows a functionally stable osteosynthesis in the condylar neck region of the mandible and that this type of osteosynthesis can resist physiologic strains in the injured temporomandibular joint as described by Gunter lauer et al. ${ }^{14}$ In all the ten cases, a retromandibular incision was used to expose the condyle, fracture site identified and fixed using Lambdoid-shaped plate. All the clinical subjects studied showed excellent stability and reduction in the condylar region. Recovery to function was immediate and postoperative IMF period was minimal. Literature reveals similar results with the use of lambda plates. ${ }^{15}$

\section{CONCLUSION:}

Thus from the study, it is conclusively demonstrated that lambda plates provide excellent rigid internal fixation in subcondylar fractures with minimal post operative complications and favorable fracture healing. 
A study using lambda plates in a larger sample size would be the further recommendation of the study.

\section{REFERENCES:}

1. Chaurasia A, Katheriya G. Prevalence of mandibular fracture in patients visiting a tertiary dental care hospital in North India. National journal of maxillofacial surgery. $2018 \mathrm{Jul} ; 9(2): 123$

2. Sawazaki R, Júnior SM, Asprino L, Moreira RW, De Moraes M. Incidence and patterns of mandibular condyle fractures. Journal of Oral and Maxillofacial Surgery. 2010 Jun 1;68(6):1252-9.

3. Cortelazzi R, Altacera M, Turco M, Antonicelli V, De Benedittis M. Development and clinical evaluation of MatrixMANDIBLE subcondylar plates system (Synthes). Craniomaxillofacial trauma \& reconstruction. 2015 Jun;8(02):094-9.

4. Albogha MH, Mori Y, Takahashi I. Three-dimensional titanium miniplates for fixation of subcondylar mandibular fractures: Comparison of five designs using patient-specific finite element analysis. Journal of Cranio-Maxillofacial Surgery. 2018 Mar 1;46(3):391-7

5. Alyahya A, Ahmed AB, Nusair Y, Ababtain R, Alhussain A, Alshafei A. Mandibular condylar fracture: a systematic review of systematic reviews and a proposed algorithm condylar fracture: a systematic review of systematic reviews and a proposed algorth

6. Loukota RA, Eckelt U, De Bont L, Rasse M. Subclassification of fractures of the condylar process of the mandible. Br J Oral MaxillofacSurg 2005;43(1):72-73

7. Cortelazzi R, Altacera M, Turco M, Antonicelli V, De Benedittis M: Development and Clinical Evaluation of MatrixMANDIBLESubcondylar Plates System (Synthes).Craniomaxillofac Trauma Reconstr 8:94, 2015

8. Urpo Silvennoinen, Tateyuki Iizuka, Christian Linqvist, Kyosti Oikarinen. Different patterns of condylar fractures: An analysis of 382 patients in a 3-year period. Journal of Oral and Maxillofacial Surgery 50: 1032-1037, 1992

9. Andre H. Montazem, George Anastassov. Management of condylar fractures. Atlas of Oral and Maxillofacial Surgery Clinics of North America 17 (2009) 55-69.

10. Byung-Ho-Choi, Choong-Kook Yi, Jae-Ha Yoo. Clinical evaluation of 3 types of plate osteosynthesis for fixation of condylar neck fractures. Journal of Oral and Maxillofacial Surgery 59: 734-737, 200

11. Christophe Meyer, Emilie Martin, Jean-Luc Kahn, Simone Zink. Development and biomechanical testing of a new osteosynthesis plate (TCP) designed to stabilize mandibular condyle fractures. Journal of Cranio-Maxillofacial Surgery 2007; 35, 84-90.

12. Christophe Meyer, Leila Serhir, Philippe Boutemi. Experimental evaluation of three osteosynthesis devices used for stabilizing condylar fractures of the mandible. Journal of Cranio-Maxillofacial Surgery 2006; 34, 173-181.

13. Christophe Meyer, Simone Zink, Brice Chatelain, Astrid Wilk. Clinical experience with osteosynthesis of subcondylar fractures of the mandible using TCP plates. Journal of Cranio-Maxillofacial Surgery 2008; 36, 260-268.

14. Lauer G, Haim D, Proff P, Richter G, Pradel W, Fanghänel J, Pilling E, Gedrange T, Mai R. Plate osteosynthesis of the mandibular condyle. Annals of AnatomyAnatomischerAnzeiger. 2007 Jul 11;189(4):412-7

15. Smolka W, Liokatis P, Cornelius CP. Open Reduction and Internal Fixation of Unilateral Mandibular Condylar Base and Neck Fractures Using a Lambda Plate: Selection Criteria for Application. Journal of Oral and Maxillofacial Surgery. 2020 Feb 11. 